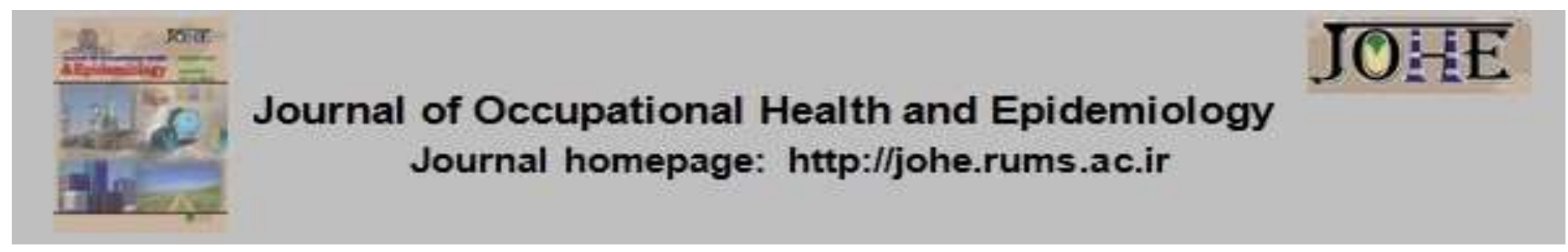

\title{
Differences among official statistics of mortality rates in Iran
}

\author{
Mehran Rostami ${ }^{1}$, Bashir Nazparvar ${ }^{2}$, Shahab Rezaeian ${ }^{3 *}$ \\ 1- MSc in Epidemiology, MPH in Prevention and Control of Addiction, Deputy for Treatment, Kermanshah University of Medical \\ Sciences, Kermanshah, Iran. \\ 2- MD, Research Department, Iranian Legal Medicine Organization, Tehran, Iran. \\ 3-Phd in Epidemiology, Research Center for Environmental Determinants of Health, School of Health, Kermanshah University of \\ Medical Sciences, Kermanshah, Iran.
}

\author{
Article Info \\ * Corresponding author: Shahab Rezaeian, \\ E-mail: shahab.rezayan@gmail.com \\ Article history \\ Received: Nov, 2018 \\ Accepted: Dec, 2018 \\ 10.29252/johe.7.4.192
}

Print ISSN: 2251-8096

Online ISSN: 2252-0902

Peer review under responsibility of Journal of Occupational Health and Epidemiology

\section{Dear Editor,}

Death indicators and causes of death are both closely associated with socio-cultural, economic, and structural factors and determinants of health, with all of which being at the core of the planning, monitoring, and assessment of intervention programs in any healthcare system (1). In Iran, the diagnosis and official registration of deaths are carried out by two independent organizations. These two organizations are medical universities, which are under the supervision of the Ministry of Health and Medical Education (MoHME), and the Forensic Medicine Organization (FMO), which is under the supervision of the Judiciary. The death registration system (DRS) managed by the MoHME suffers from several shortcomings, including inconsistency in DRS administration, the duplicate recording and misclassification of deaths, geographical misalignment, the incompleteness of records, and missing values (2). Given the shortcomings mentioned, the inaccuracy and duplication of the official statistics of the mortality rate throughout the country are probable on the part of different official sources.

In this review, an outline of some of the cases with considerable differences between the mortality statistics registered by the MoHME and by the FMO has been presented. Because of the importance of death events and the respective consequences, the legislator has assigned tasks, such as the issuance of death certificates and the determining of the causes of some deaths, to the FMO, under the following conditions:

a) For all cases mentioned in Table 1, a death certificate will be issued by a forensic physician.

b) For the cases of death that occur less than 24 hours after the admission of the patient to the hospital, the forensic physician issues a death certificate.

c) For the cases of death occurring more than 24 hours after the admission of the patient to the hospital, the hospital physician issues a death certificate after consulting with the forensic physician. 
d) The Cemetery Organization shall only accept the certificates issued, signed, and sealed by hospital physicians or forensic physicians and shall refrain from accepting other certificates.

Regarding the deaths occurring outside hospitals and health centers, especially in remote rural areas, verbal autopsy questionnaires are used in order to improve the quality of information about the causes of deaths, being performed by physicians $(1,3)$. In such cases, hospital physicians are not authorized to issue death certificates, since it can lead to incompatibility between the two official datasets. The possible solution to the problem could be establishing an effective and accurate relationship between the MoHME's dataset and that of the FMO. In fact, based on the instructions of the Judicial System of Iran, the causes of deaths must be written in Persian on the death certificate issued by the forensic physicians; codes or English words not allowed to be written. In other words, the causes of deaths cannot be written in abbreviated forms by forensic physicians (4). To improve this relationship, closer cooperation between provincial health administrations and provincial forensic medicine centers is required so as to update and correct death statistics to address the underestimations of the mortality data. In addition, there is a need for organizing a technical team from the two abovementioned organizations to check the statements related to the causes of deaths on death certificates against the ICD-10 codes for higher accuracy. Another possible solution could be the use of the FMO's data in cases where the researcher intends to study the deaths whose certificates are issued by the FMO. This solution prevents the underestimation of the cases of deaths, however, researchers' authority is limited in this case in terms of the variety of deaths. However, death registration by the FMO's dataset does not provide full coverage of the deaths throughout the country (1).

Table 1: The cases of death for which a death certificate will be issued by a forensic physician

\begin{tabular}{cl}
\hline 1 & Homicide and complete suicide \\
\hline 2 & Deaths following any conflict or violence \\
\hline 3 & Deaths caused by cold weapons or firearms \\
\hline 4 & Deaths caused by traffic accidents and any other accident (in any form and at any time) \\
\hline 5 & Deaths caused by poisoning, chemicals, medications, gases, etc. \\
\hline 6 & Drug overdose deaths \\
\hline 7 & Deaths caused by unexpected events, including earthquakes, floods, natural disasters, frostbite, heat stroke, \\
\hline 8 & lightning, etc. \\
\hline 9 & Derk-related deaths, including the ones caused by occupational accidents \\
\hline 10 & Deaths on the streets and public places \\
\hline 11 & Maternal deaths due to diagnostic and therapeutic measures during pregnancy, childbirth, or after abortion \\
\hline 12 & Deaths during or after exercise \\
\hline 13 & Sudden, unexpected, and unexplained deaths \\
\hline 14 & Deaths arising from claims \\
\hline 15 & Suspicious deaths and deaths due to an unknown cause \\
\hline 16 & Deaths of unknown people \\
\hline 17 & Deaths that seem to be resulted by crimes \\
\hline 18 & The death of foreigners (people of foreign nationalities) \\
\hline
\end{tabular}

\section{Acknowledgement}

The authors would like to thank Dr. Mohammad Karamouzian (University of British Columbia, BC Vancouver, Canada) to improve the English writing.

Conflict of interest: None declared.

\section{References}

1. Khosravi A, Aghamohamadi S, Kazemi E, Pourmalek F, Shariati M. Mortality Profile in Iran (29 provinces) over the years 2006 to 2010. Tehran: Ministry of Health and Medical Education; 2012. p.7-21.
2. Sheidaei A, Gohari K, Kasaeian A, Rezaei N, Mansouri A, Khosravi A, et al. National and subnational patterns of cause of death in Iran 1990-2015: Applied methods. Arch Iran Med 2017; 20(1):2-11.

3. Aghamohammadi S, Kazemi E, Khosravi A, Kazemeini $\mathrm{H}$. The trend of ten leading causes of death in the Islamic Republic of Iran, 2006- 2011. Iranian Journal of Epidemiology 2017; 12(4):111.

4. Rostami M, Mohammadi Y, Jalilian A, Nazparvar B. Modeling spatio-temporal variations of substance abuse mortality in Iran using a logGaussian Cox point process. Spat Spatiotemporal Epidemiol 2017; 22:15-25. 